And as the quality of the hair is a much more durable feature than the complexion, or almost any other physical trait, the necessity of separating the Ainos from the Mongolic stock becomes all the more obvious. If all this, combined with a distinct orthognathism, mesocephalic head (index No. 76), a light complexion, often scarcely darker than that of Europeans, brown iris, large well-shaped nose, and low cheek bones, is not sufficient to affiliate them to the Caucasic stock, then anthropologists must discover some other sufficiently differentiated physical type with which to group them. That various branches of the Caucasic race reached the East Asiatic seaboard in prehistoric times has been pointed out by this writer in a recent paper on the Koreans (see Nature, vol. xxvi , p. 344). From Korea to the Japanese Archipelagos, the transition is easy, although it is not pretended that the line of migration necessarily follow ed this route. But enough has perhaps been stated to show that there is nothing extravagant in the theory of a Caucasic origin of the Aino race. Some of the intermediate links between them and their western kinsmen have already been brought to light. The others must be looked for in the still unexplored uplands of South-west China and Further India.

It is also to be noticed that the Ainos can only in a relative sense be regarded as the Aborigines of Yeso and Nippon. Scheube tells us that they are entirely ignorant of the potter's art (p. II). But abundance of ancient pottery, often highly ornamented, has been found in many parts both of Hondo and Yeso. These remains are referred by the Ainos themselves to the extinct Koro-pokGuru, or "People of the Hollows." their precursors in Yeso, who dwelt in huts built over pits, and who had a knowledge of pottery. The Japanese also refer the pits found on an island near Nemuro, north-east coast of Yeso, to the Kohito, a dwarfish race, said to have been exterminated by the Ainos, and apparently identical with the Koro-pok-Guru. It becomes a question whether with these potters, rather than with the Ainos, are to be associated the earthenware and other prehistoric remains found by Milne in the kitchen middens of the Tokio district and other parts of Japan. These remains show clear traces of cannibalism, a practice which seems entirely alien from the mild and inoffensive disposition of the Ainos.

But however this be, the present Aborigines seem destined at no distant date to disappear like their predecessors. The total number of full blood Ainos is estimated by Scheube at about 17,000 for Yeso, to which must be added, perhaps, rooo or 1500 for Sakhalin and the Kuriles. Siebold, however, thinks that one-third of the inhabitants of Yeso, say 45,000 altogether, are either pure or half-caste Ainos. But the former are known to have decreased in the government of Sapphoro from over 16,000 in $187 \mathrm{I}$, to 13,326 in 1878 , while the latter seem to be correspondingly on the increase. The result is inevitable-the effacement of the Ainos as a distinct nationality, and their ultimate absorption in the dominant race. The process that has been completed in Nippon is in rapid progress in Yeso.

A. H. KEANE

\section{ON A NEW ARC ELECTRIC LAMP}

FLECTRIC lamps on the arc principle are almost as I. numerous as the trees in the forest, and it is somewhat fresh to come upon something that is novel. In these lamps the carbons are consumed as the current flows, and it is the variation in their consumption which occasions the flickering and irregularity of the light that is so irritating to the eyes. Special mechanical contrivances or regulators have to be used to compensate for this destruction of the carbons, as in the Siemens and

I Paper read at the British Association, Southampton. Revised by the
Brush type, or else refractory materials have to be combined with the carbons, as in the Jablochkoff candle and in the lamp Soleil. The steadiness of the light depends upon the regularity with which the carbons are moved towards each other as they are consumed, so as to maintain the electric resistance between them a constant quantity. Each lamp must have a certain elasticity of regulation of its own, to prevent irregularities from the variable material of carbon used, and from variations in the current itself and in the machinery.

In all electric lamps, except the Brockie, the regulator is in the lamp itself. In the Brockie system the regulation is automatic, and is made at certain rapid intervals by the motor engine. This causes a periodic blinking that is detrimental to this lamp for internal illumination.

M. Abdank, the inventor of the system which I have the pleasure of bringing before the Section, separates his regulator from his lamp. The regulator may be fixed

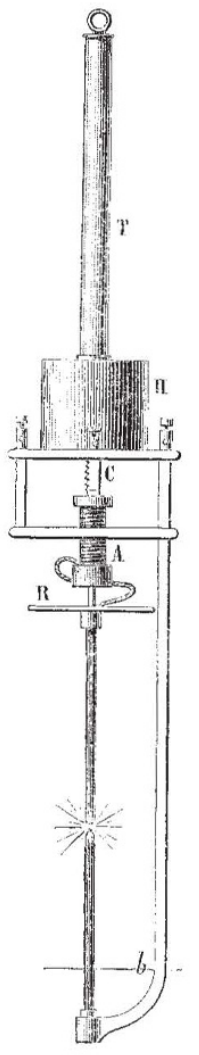

FrG. r.

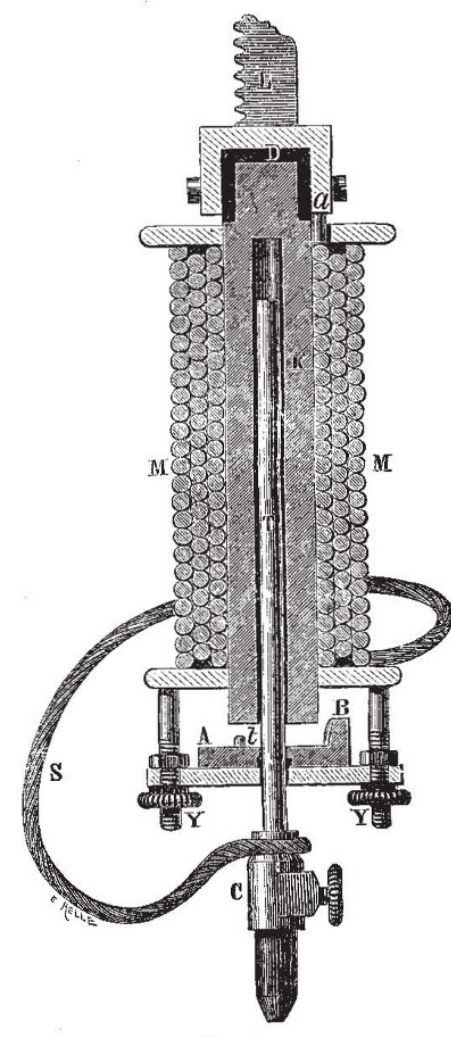

FrG. 2. anywhere, within easy inspection and manipulation, and away from any disturbing influence in the lamp. The lamp can be fixed in any inaccessible place.

The I amp (Figs. I, 2, and 3).-The bottom or negative carbon is fixed, but the top or positive carbon is movable, in a vertical line. It is screwed at the point $\mathrm{C}$ to a brass rod, $\mathrm{T}$ (Fig. 2), which moves freely inside the tubular iron core of an electromagnet, $\mathrm{K}$. This rod is clutched and lifted by the soft iron armature, A B, when a current passes through the coil, M M. The mass of the iron in the armature is distributed so that the greater portion is at one end, B, much nearer the pole than the other end. Hence this portion is attracted first, the armature assumes an inclined position, maintained by a brass button, $t$, which prevents any adhesion between the armature and the core of the electromagnet. The electric connection between the carbon and the coil of the electromagnet is maintained by the flexible wire, $\mathrm{s}$. 
The electromagnet, A (Fig. I), is fixed to a long and beavy rack, $\mathrm{C}$, which falls by its own weight and by the weight of the electromagnet and the carbon fixed to it. The length of the rack is equal to the length of the two carbons. The fall of the rack is controlled by a friction break, В (Fig. 3), which acts upon the last of a train of three wheels put in motion by the above weight. The

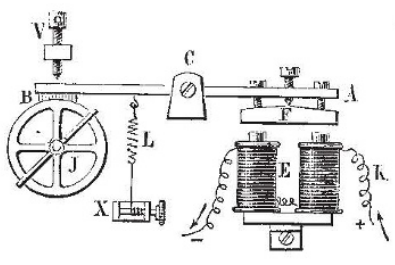

F16. 3

break, $\mathrm{B}$, is fixed at one end of a lever, B A, the other end carrying a soft iron armature, F, easily adjusted by three screws. This armature is attracted by the electromagnet, $\mathrm{EE}$ (whose resistance is $\mathrm{I} 200 \mathrm{ohms}$ ), whenever a current circulates throush it. The length of the play is regulated by the screw, V. The spring, L, applies tension to the break.

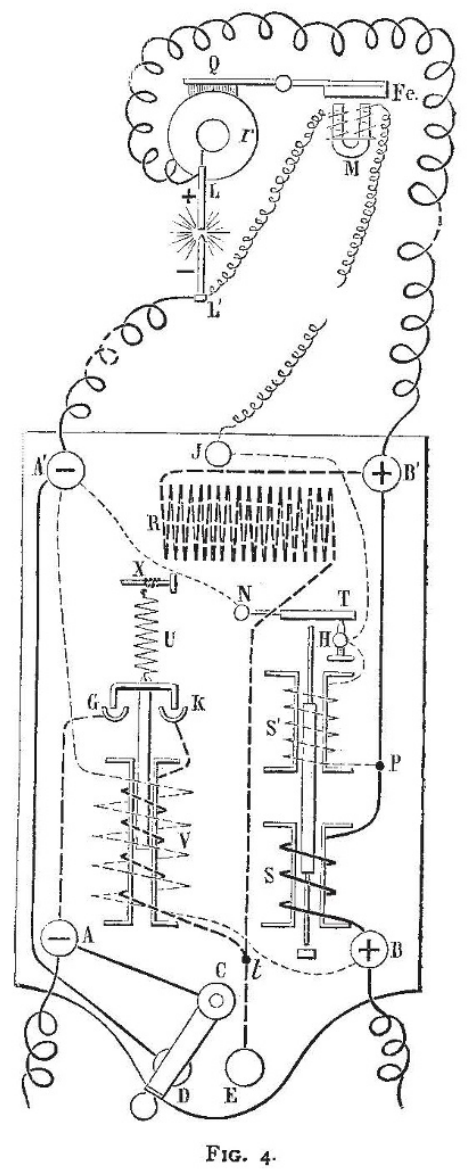

The Regulator.-This consists of a balance and a cut-off.

The Balance (Figs. 4 and 5) is made with two solenoids, $s$ and $s^{\prime}$, whose relative resistances is adjustible. $\mathrm{S}$ conveys the main current, and is wound with thick wire having practically no resistance, and $S^{\prime}$ is traversed by a shunt current, and is wound with fine wire having a resistance of 600 ohms. In the axes of these two coils a small and light iron tube $(2 \mathrm{~m} . \mathrm{m}$. diameter and $60 \mathrm{~m} . \mathrm{m}$. length) freely moves in a vertical line between two guides. When magnetised it has one pole in the middle and the other at each end. The upward motion is crontrolled by the spring $\mathrm{N}_{\mathrm{T}}$. The spring rests upon the screw, $\mathrm{H}$, with which it makes contact by platinum electrodes. This contact is broken whenever the little iron rod strikes the spring, $\mathrm{N}$ T.

The positive lead from the dynamo is attached to the terminal, $\mathrm{B}$, then passes through the coil, $\mathrm{S}$, to the terminal, $B^{\prime}$, whence it proceeds to the lamp. The negative

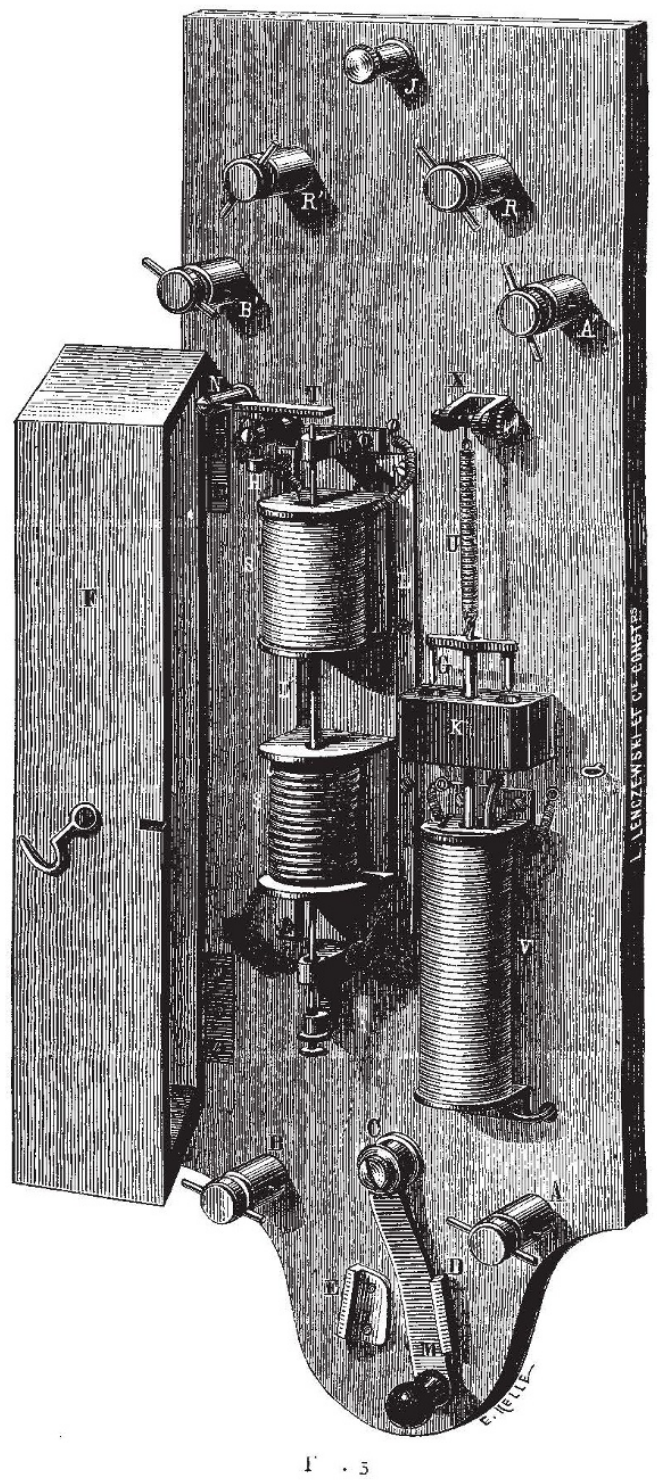

lead is attached to terminal A, passing directly to the other terminal, $\mathrm{A}^{\prime}$, and thence to the lamp.

The shunt which passes through the fine coil, $\mathrm{s}^{\prime}, \mathrm{com}-$ mences at the point, $P$. The other end is fixed to the screw, $\mathrm{H}$, whence it has two paths, the one offering no resistance through the spring, $\mathrm{T} N$, to the upper negative terminal, $\mathrm{A}^{\prime}$; the other through the terminal, $\mathrm{J}$, to the electromagnet of the break, $M$, and thence to the negative terminal of the lamp, $\mathrm{L}^{\prime}$.

The Cut-off.-The last part of the apparatus (Fig. 4) to be described is the cut-off, which is used when there are 
several lamps in series. It is brought into play by the switch, C D, which can be placed at E or D. When it is at $\mathrm{E}$, the negative terminal, $\mathrm{A}$, is in communication with the positive terminal, $\mathrm{B}$, through the resistance, $\mathrm{R}$, which equals the resistance of the lamp, which is therefore out of circuit. Whe it is at D the cut-off acts automatically to do the same thing when required. This is done by a solenoid, $\mathrm{v}$, which has two coils, the one of thick wire offering no resistance, and the other of $2000 \mathrm{ohms}$ resistance. The fine wire connects the terminals, $\mathrm{A}^{\prime}$ and $\mathrm{B}$. The solenoid has a movable soft iron core suspended by the spring, $U$. It has a cross piece of iron which can dip into two mercury cups, G and $\mathrm{K}$, when the core is sucked into the solenoid. When this is the case, which happens when any accident occurs to the lamp, the terminal, A, is placed in connection with the terminal, $\mathrm{B}$, through the thick wire of $V$ and the resistance, $R$, in the same way as it was done by the suitch, C D.

Electrical Arrangement.-The mode in which several lamps are connected up in series is shown by Fig. 6 . M is the dynamo-machine. The + lead is connected to $B_{1}$ of the balance, it then passes to the lamp, L, returning to the balance, and then proceeds to each other lamp, returning finally to the negative pole of the machine. When the current enters the balance it passes through the coil, $\mathrm{s}$, magnetising the iron core and drawing it downwards (Fig. 4). It then passes to the lamp, L L', through the carbons, then returns to the balance, and proceeds back to the negative terminal of the machine. A small portion of the current is shunted off at the point, $\mathrm{P}$, passing through the coil, $\mathrm{s}^{\prime}$, through the contact srring, $\mathrm{T} N$, to

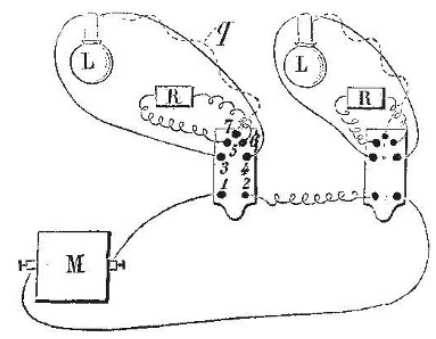

FIG. 6.

the terminal, $\mathrm{A}^{\prime}$, and drawing the iron core in opposition to $\mathrm{S}$. The carbons are in contact, but in passing through the lamp the current magnetises the electromagnet, $M$ (Fig. 2), which attracts the armature, $\mathrm{A} B$, that bites and lifts up the rod, $T$, with the upper carbon a definite and fixed distance that is easily regulated by the screws, $\mathrm{Y} Y$. The arc then is formed, and will continue to burn steadily as long as the current remains constant. But the moment the current falls, due to the increased resistance of the arc, a greater proportion passes through the shunt, $\mathrm{S}^{\prime}$ (Fig. 4), increasing its magnetic moment on the iron core, while that of $\mathrm{s}$ is diminishing. The result is that a moment arrive; when equilibrium is destroyed, the iron rod strikes smartly and sharply upon the spring, $\mathrm{N}$ T. Contact between $\mathrm{T}$ and $H$ is broken, and the current passes through the electromagnet of the break in the lamp. The break is released for an instant, the carbons approach each other. But the same rupture of contact introduces in the shunt a new resistance of considerable magnitude (viz. I $200 \mathrm{ohms}$ ), that of the electromagnets of the break. Then the strength of the shunt current diminishes considerably, and the solenoid, $\mathrm{S}$, recovers briskly its drawing power upon the rod, and contact is restored. The carbons approach during these periods only about $\mathrm{O} 1$ to $\mathrm{O} 2$ millimetre. If this is not sufficient to restore equilibrium it is repeated continually, until equilibrium is obtained. The result is that the carbon is continually falling by a motion invisible to the eye, but sufficient to provide for the consumption of the carbons.
The contact between $\mathrm{NT}$ and $\mathrm{H}$ is never completely broken, the sparks are very feeble, and the contacts do not oxidise. The resistances inserted are so considerable that heating cannot occur, while the portion of the current abstracted for the control is so small that it may be neglected.

The balance acts precisely like the key of a Morse machine, and the break precisely like the sounder-receiver so well known in telegraphy. It emits the same kind of sounds, and acts automatically like a skilled and faithful telegraphist.

This regulation, by very small and short successive steps offers several advantages: ( $\mathrm{I}$ ) it is imperceptible to the eye ; (2) it does not affect the main current; (3) any sudden, instantaneous, variation of the main current does not allow a too near approach of the carbon points.

Let now an accident occur, for instance, a carbon is broken. At once the automatic cut-off acts, the current passes through the resistance $R$ instead of passing through the lamp. The current through the fine coil is suddenly increased, the rod is drawn in, contact is made at G and $\mathrm{K}$, and the current is sent through the coil, $\mathrm{R}$. As soon as contact is again made by the carbons, the current in the coil $\mathrm{S}$ is increased, that of the thick wire in $\mathrm{V}$ diminished, and the antagonistic spring, $U$, breaks the contact at $\mathrm{G}$ and $\mathrm{K}$. The rupture of the light is almost invisible, because the relighting is so brisk and sharp.

I have seen this lamp in action, and its constant steadiness leaves nothing to be desired. W. H. PREECE

\section{THE SANITARY INSTITUTE}

THE Inaugural Address delivered by Captain Douglas Galton at the opening of the Congress of the Sanitary Institute of Great Britain at Newcastle-upon-Tyne, traces the growth of the more important questions relating to public health and to the prevention of disease from remote times down to recent date, and it is, both historically and otherwise, of much interest. Questions of public health have for many years past received increasing attention in this and other countries, and the energies of some of the ablest intellects have been devoted to the investigation of the various circumstances which tend to injure the health of communities. Some have dealt with the subject from a purely scientific point of view, others have given their attention especially to the defects in works of construction, such as systems of sewerage and water-supply, which have led to the spread of disease, and many physicians have devoted themselves exclusively to those branches of medical science which deal with preventive as opposed to curative medicine. Captain Galton refers to many of these researches, and shows how they have tended to secure for us our present knowledge. Dr. Tyndall's well-known investigations as to the existence of low forms of life in the dust contained in air, and his studies on putrefaction are recorded, as also Dr. Bastian's and Mr. Lister's kindred labours, and the practical applications to which they may be put. The several discoveries as to the connection of disease with definite organisms are noted; Professor Koch's recent contributions as to the organisms assoriated with tubercular disease closing this subject, in point of time. $M$. Pasteur's discoveries in connection with fowlcholera and anthrax in cattle, and the associated question of the attenuation of the infectious property of the virus of these diseases, as the result of the processes to which they are subjected are dealt with in some detail. As to accepting M. Pasteur's conclusions in their entirety, it may however be desirable to await further experiments, the more so as certain investigations of Dr. Klein, an account of which has recently been submitted by the Local Government Board to the Veterinary Department of the Privy Council, have tended to conclusions adverse to the general adoption of M. Pasteur's proposal to inoculate 